\title{
New products and services briefing
}

Listings are prepared from information supplied by the companies cited or by their agents and are presented for informational value only. Publication in no way constitutes endorsement or warranty by The Journal of the American Osteopathic Association or by the American Osteopathic Association. In contacting the companies, please mention JAOA.

\section{Reference of prescription options}

The pocketbook Indications Index (ivi) lists drugs indicated for treating more than 2000 specific diseases, disorders, and complaints. The index includes ophthalmological medications and over-the-counter drugs. All entries feature the brand name as well as the drug's active ingredients. For more information, contact Medical Economics Data, 680 Kinderkamack Rd, Oradell, NJ 07649; (201) 262-3030, or (800) 526-4870.

\section{Wheelchair}

The Self-Reliant Wheelchair can be used over a commode. The midsection of the seat opens with the turn of a lever and drops 1 in. The sitter then can manually pull the center seat section out of the way. The foldable chair features high-density foam cushions covered with washable upholstery. For more information, contact Technovation Inc, $1003 \mathrm{~W}$ College Ave, Appleton, WI 54914 ; (414) $731-6106$, or (800) 447-6339.

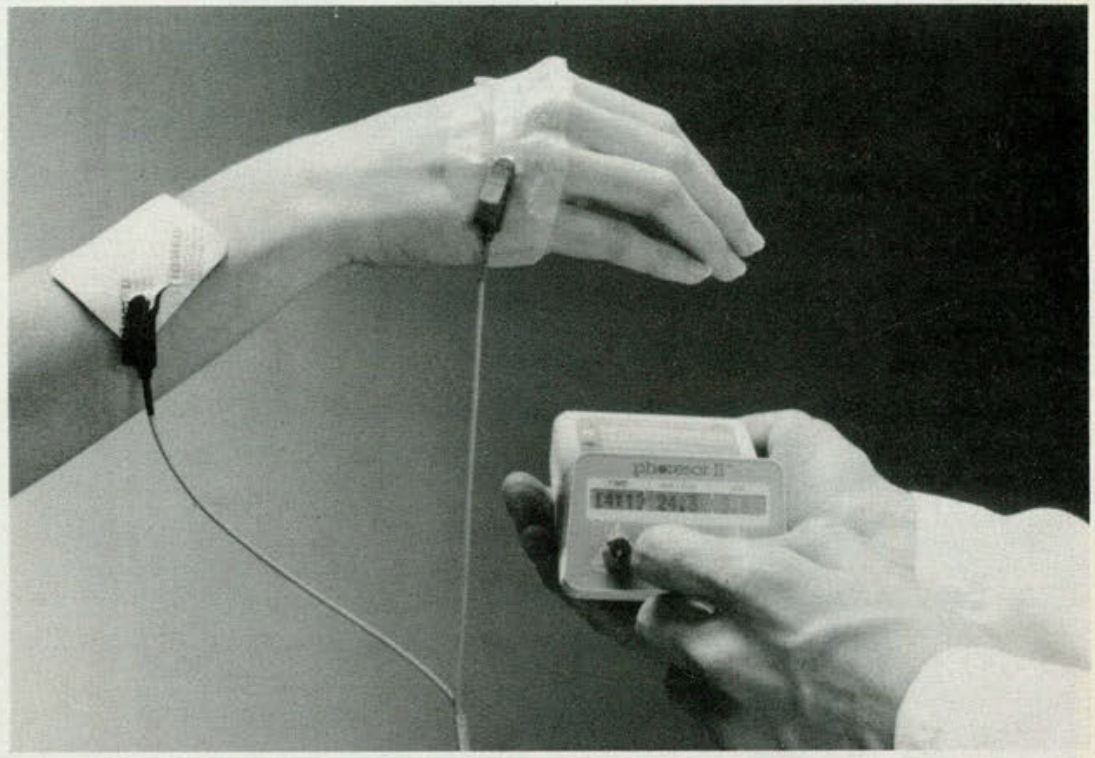

The TransQ ${ }^{I}$ electrode delivers local anesthesia as well as drugs intended to treat inflammatory disorders.

\section{Iontophoretic drug delivery electrode}

Intended for use in treating patients with inflammatory disorders or as a means of delivering local anesthesia, the TransQ 1 drug delivery electrode is compatible with the Phoresor ${ }^{\circledR}$ iontophoretic drug delivery system. The electrode has a polymer gel pad that the clinician fills with medication and applies to the prepared treatment area like a bandage. The pliable material adheres to contoured areas. For more information, contact Iomed, Inc, 1290 W 2320 South, Suite A, Salt Lake City, UT 84119; (801) 975-1191, or (800) 621-3347.

\section{Blood perfusion monitor}

The LaserFlo ${ }^{\circledR} \mathrm{BPM}^{2}$ blood perfusion monitor uses laser and fi- beroptic technology to provide continuous circulation information in real time presentation. Operators may choose from a graphic and numeric menu-driven format. The monitor allows the operator to customize the parameters for each individual monitoring situation. A low-level alarm warns attending staff of circulation compromise. The device may be used as a clinical and research monitoring system. For more information, contact Vasamedics Inc, 2963 Yorkton Blvd, St Paul, MN 55117-1064; (612) 490-0999.

\section{Hormone injection for endometriosis}

A synthetic analog of the naturally occurring gonadotropin-releasing hormone, Lupron ${ }^{\circledR}$ Depot (leuprolide acetate) is intended for use in treating women with 


\section{"Doctor,}

can you tell

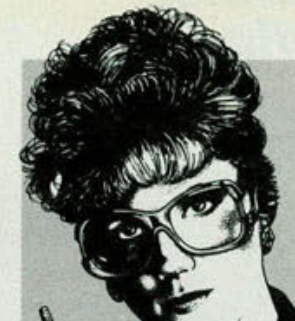

me more

about...?"

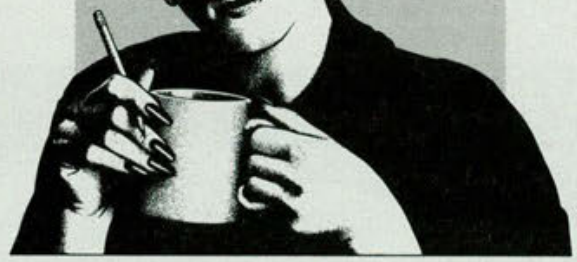

Today's patients are becoming increasingly health conscious. And they want health information from a reliable source-you, their family practitioner. But you

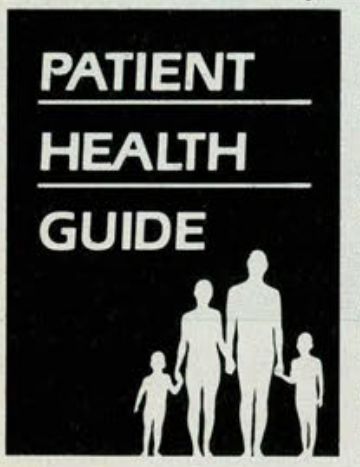
might not always have the time to answer all of their questions. That's where the "Patient health guide" can help. Published regularly in The $D O$, this column addresses your patients' physical, behavioral and psychosocial concerns in easy-to-understand language. It is meant to supplement, not replace, your professional expertise.

So tell us what your patients are asking you and what common health misconceptions you have encountered. Print or type your comments below or on a separate sheet of paper, and send them to:

Editor, "Patient health guide," The DO $142 \mathrm{E}$ Ontario St

Chicago, IL 60611-2864.

With your input, the "Patient health guide" can help you to promote health and prevent disease among your patients.

Name

Street address

City, state and ZIP code

Telephone (optional)

Your comments 